\title{
Retention of endoscopic capsule in an umbilical hernia
}
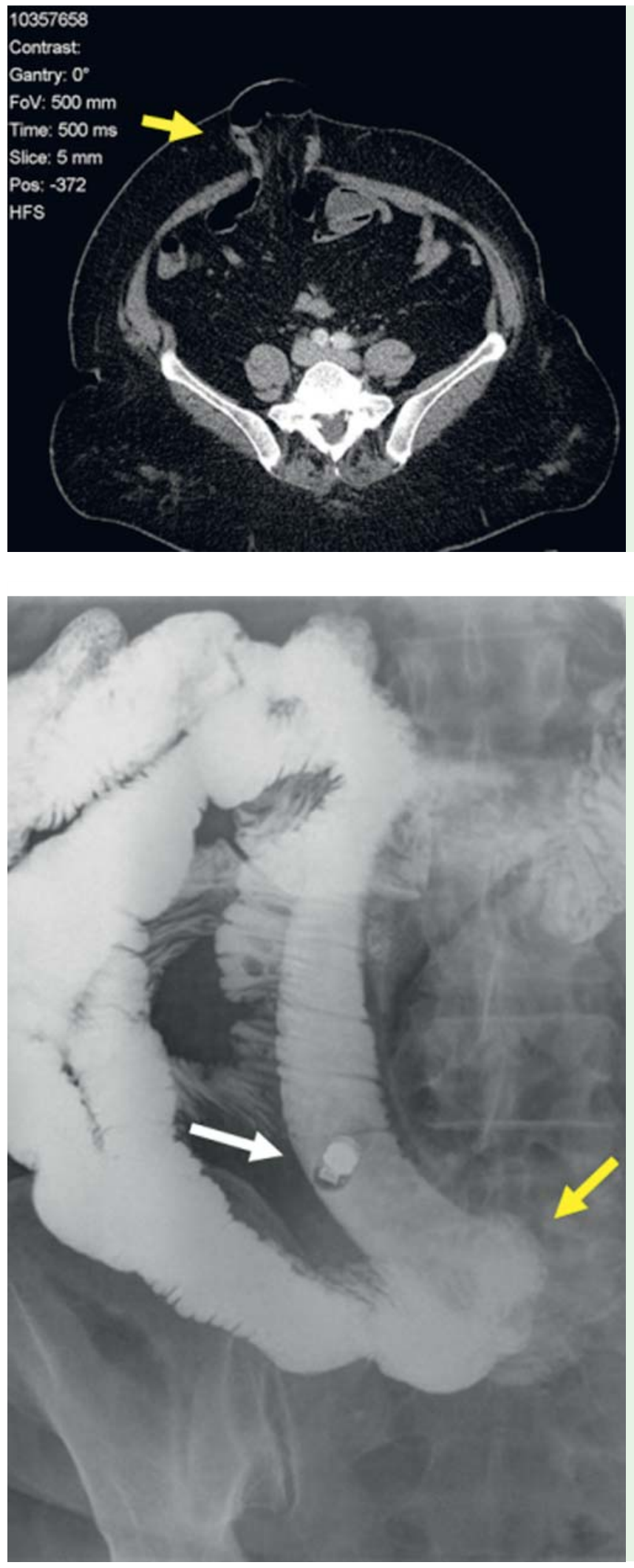

Fig. 1 Computed tomography (CT) enteroclysis showing the umbilical hernia (yellow arrow) with a bowel loop within.

Fig. 3 Small-bowel radiograph with watersoluble contrast showing retained capsule (white arrow) in relation to an umbilical hernia (yellow arrow). 
in the umbilical hernia and ruled out stenosis or signs of small-bowel obstruction (๑ Fig. 3).

After 16 days of capsule retention, a hernioplasty was performed and the capsule was spontaneously expelled afterwards.

Retention of an endoscopic capsule is a rare complication. There are a few case reports of capsule retention in different types of digestive diverticulum [2-4] but, to the best of our knowledge, this is the first case of capsule retention in an umbilical hernia. Current recommendations do not consider these entities as contraindications for capsule endoscopy [5], but the gastroenterologist should keep in mind the potentially increased risk of capsule retention.

Endoscopy_UCTN_Code_CPL_1AI_2AB

Competing interests: None

\section{F. Ferreira, P. Bastos, H. Cardoso,}

A. C. R. Nunes, G. Macedo

Gastroentrology Department, Hospital

S. João and Faculty of Medicine, Porto,

Portugal

\section{References}

1 Liao Z, Gao R, Xu C, Li ZS. Indications and detection, completion, and retention rates of small-bowel capsule endoscopy: a systematic review. Gastrointest Endosc 2010; 71: 280-286

2 Ordubadi P, Blaha B, Krampla $W$ et al. Capsule endoscopy with retention of the capsule in a duodenal diverticulum. Endoscopy 2008; 40: $247-248$

3 Giday SA, Pickett-Blakely OE, Buscaglia JM, Mullin GE. Capsule retention in a patient with small-bowel diverticulosis. Gastrointest Endosc 2009; 69: 384-386

4 Tanaka Y, Motomura Y, Akahoshi Ket al. Capsule endoscopic detection of bleeding Meckel's diverticulum, with capsule retention in the diverticulum. Endoscopy 2010; 42: 199-200
5 Ladas SD, Triantafyllou K, Spada C et al. European Society of Gastrointestinal Endoscopy (ESGE): recommendations (2009) on clinical use of video capsule endoscopy to investigate small-bowel, esophageal and colonic diseases. Endoscopy 2010; 42: 220 - 227

\section{Bibliography}

DOI $10.1055 / \mathrm{s}-0030-1256140$

Endoscopy 2011; 43: E111 -E112

(c) Georg Thieme Verlag KG Stuttgart · New York . ISSN 0013-726X

\section{Corresponding author}

\section{F. Ferreira}

Hospital de São João - Serviço de Gastrenterologia Alameda Professor Hernâni Monteiro

4200-319 Porto

Portugal

Fax: +351-22-5507742

fredericoferreira2@hotmail.com 